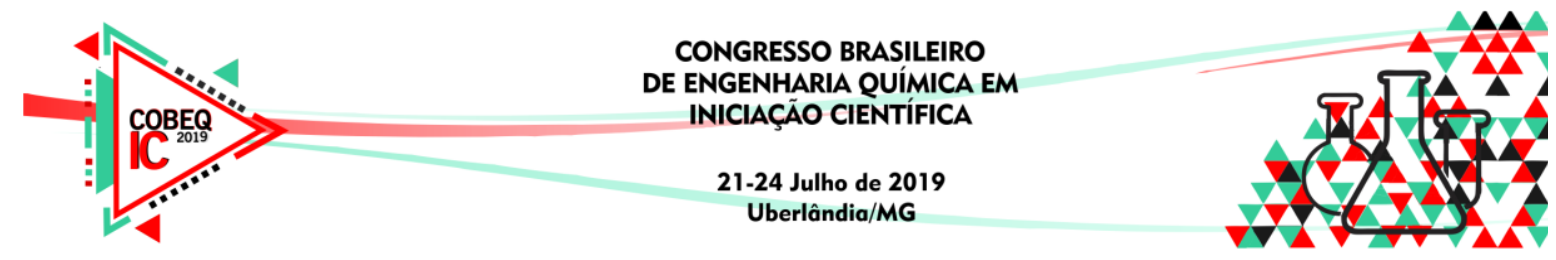

\title{
EFEITO DE DIFERENTES TEMPERATURAS DE PIRÓLISE DA BORRA DE CAFÉ NO TRATAMENTO DE EFLUENTES CONTAMINADOS PELO PESTICIDA THIAMETHOXAM
}

\author{
A. F. D. Gonçalves ${ }^{2}$, C. A. Silva ${ }^{2}$, M.C.P. Alves ${ }^{2}$, M.E.F. Fonseca², V. F. Knupp ${ }^{1}$ \\ Universidade Federal de São João Del Rei, Campus Alto Paraopeba, Departamento de \\ Química, Biotecnologia e Engenharia de Bioprocessos ${ }^{1}$, Curso de Engenharia Química ${ }^{2}$. \\ E-mail para contato: cesar.augstsilva@gmail.com
}

RESUMO - Foi estudada a capacidade de adsorção da borra de café pirolisada a 500 e $800^{\circ} \mathrm{C}$ na remoção do inseticida thiamethoxam em solução aquosa. Foram realizados testes adsortivos que avaliaram a influência do $\mathrm{pH}$, da massa de biocarvão e da concentração de thiamethoxam para o processo adsortivo. Realizou-se análise estatística dos dados e os mesmos evidenciaram que o biocarvão obtido sob pirólise a $500^{\circ} \mathrm{C}$ removeu com mais eficiência o thiamethoxam do meio aquoso.

\section{INTRODUÇÃO}

A prática da agricultura é conhecida há milhares de anos, mas o uso de agrotóxicos começou a ser utilizado a partir da Revolução Verde, quando houve uma transformação no processo da atividade agricultura, inserindo novas tecnologias que contribuíssem com o aumento da produção de alimentos. Dentre essas tecnologias, a mais marcante foi a inserção do uso dos agrotóxicos para controlar pragas e doenças das plantas afim de aumentar a produtividade (BACHA, 2004).

No Brasil, o uso dos agrotóxicos começou a partir da modernização da agricultura nacional, entre 1945 e 1985 com o apoio do governo, para facilitar a atividade agrícola e aumentar a produção (MELLO, 2006). Em 1975 através do Programa Nacional dos Defensivos Agrícolas houve a instalação da indústria de agrotóxicos no país, que ocasionou em um grande aumento da utilização dos agrotóxicos nas atividades do campo. Em 2008, o Brasil ultrapassou os Estados Unidos e assumiu o posto de maior mercado mundial de agrotóxicos (AUGUSTO, 2011).

Dentre os vários agrotóxicos consumidos no Brasil, destaca-se o thiamethoxam (3-(2cloro-tiazol-5-ilmetil), que é um inseticida sistêmico do grupo dos neonicotinóides. Devido às suas características físico-químicas (baixa sorção no solo e elevada solubilidade em água), ele apresenta alto potencial de contaminação ambiental por meio de lixiviação. A dispersão pelo ar e a contaminação de corpos hídricos, são potenciais fontes de exposição a seres humanos, podendo acontecer de forma direta ou indireta, sendo que a exposição crônica a este inseticida vem sendo estudada com resultados que sugerem correlação entre exposição e desregulação endócrina, câncer e dermatites (TAVARES, et al., 2007).

Sabendo dos problemas ambientais causados pelo uso do inseticida e os danos à saúde humana, surge a necessidade de utilização de novas tecnologias visando diminuir os impactos dos agrotóxicos no meio ambiente. Associado aos problemas ambientais causados por 


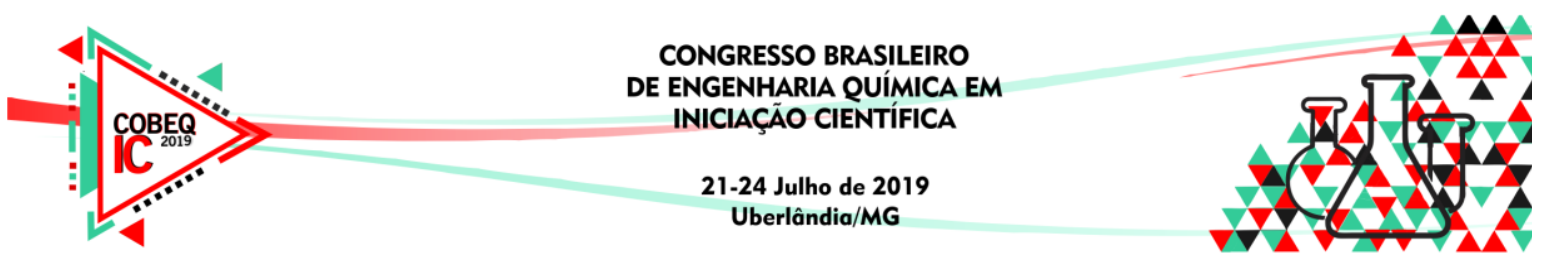

poluentes persistentes, é notório que um dos grandes desafios da indústria, de um modo geral, é saber o que fazer com os resíduos que são gerados nos processos industriais. Atualmente, verifica-se pequena reutilização desses resíduos em aplicação ambiental.

Dessa forma, sabendo que o Brasil lidera a produção e exportação mundial de café e também é o maior produtor de café solúvel segundo a ABIC, gerando uma quantidade significativa de resíduos, seria interessante utilizá-los como tecnologia para promover tratamento de efluentes contaminados por poluentes persistentes, como o pesticida thiamethoxam. Assim, neste trabalho, propõe-se purificar a água contaminada com o thiamethoxam, utilizando biocarvão produzido a partir da biomassa de borra de café, já que o Brasil produz toneladas desse resíduo.

\section{MATERIAIS E MÉTODOS}

A borra de café utilizada neste trabalho foi obtida de residências, bares e lanchonetes da cidade de Ouro Branco - MG. Inicialmente a borra de café foi lavada exaustivamente com água destilada em ebulição até que a solução filtrada ficasse incolor. Posteriormente, secou-se a borra em estufa a $80^{\circ} \mathrm{C}$ por 24 horas. A borra seca foi dividida em duas porções. A primeira foi submetida a pirólise sob temperatura de $500^{\circ} \mathrm{C}$ por duas horas, enquanto a outra parte, submetida a pirólise sob temperatura de $800^{\circ} \mathrm{C}$ pelo mesmo período. Para a realização dos processos de pirólise, usou-se o forno mufla e uma cápsula que continha as amostras, com função de manter a atmosfera inerte.

Realizou-se através do Software Statistica 8.0 um Delineamento Composto Central Rotacional, investigando-se três variáveis: concentração de thiamethoxam, massa de biocarvão e pH, com o objetivo de otimizarmos o processo de adsorção do inseticida, como mostrado na Tabela 1. Foram preparadas soluções de thiamethoxam em concentrações variadas $(33.2 ; 40,0$; 50,$0 ; 60,0$ e $66.8 \mathrm{mg} / \mathrm{L}$ ) em balões de $50 \mathrm{~mL}$, e ajustados os valores de pH. Após as soluções preparadas foram adicionadas as massas de biocarvão e agitadas por $1 \mathrm{~h}$ em um shaker à 200 $\mathrm{rpm}$ a temperatura à $25^{\circ} \mathrm{C}$. Ao fim da agitação, as amostras foram filtradas à vácuo e diluídas à 1/6 para leitura em espectrofotômetro GENESYS 10S UV-VIS, alocado no Campus Alto Paraopeba, utilizando-se cubetas de quartzo de $1,0 \mathrm{~cm}$. A determinação da concentração de thiamethoxam foi realizada através da espectroscopia no UV-VIS nos comprimentos de onda adequados: abaixo de pH 9, $254 \mathrm{~nm}$ e acima de $\mathrm{pH}$ 9, $258 \mathrm{~nm}$. Nos ensaios de pH, os ajustes

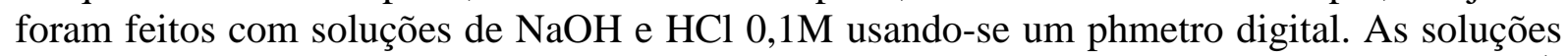
de thiamethoxam foram feitas por diluição à partir de uma solução de estoque $4000 \mathrm{mg} \mathrm{L}^{-1}$, utilizando micropipeta e avolumado em balão de $50 \mathrm{~mL}$. Para cálculo de adsorção foi usado método de padrão externo, sendo feitas soluções padrão que variaram de 30 a $70 \mathrm{mg} \mathrm{L}^{-1}$.

\section{RESULTADOS E DISCUSSÕES}

Os resultados de adsorção do thiamethoxam usando-se o biocarvão a partir da borra de café pirolisada a $500{ }^{\circ} \mathrm{C}$ e a $800^{\circ} \mathrm{C}$ são apresentados na Tabela 1. 


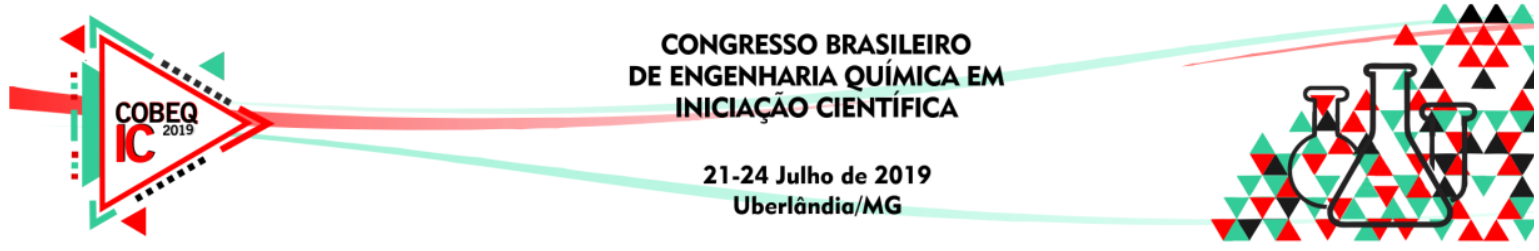

Tabela 1 - Planejamento experimental - Delineamento Composto Central Rotacional

\begin{tabular}{|c|c|c|c|c|}
\hline $\begin{array}{c}{[\text { Thiamethoxam }} \\
(\mathrm{mg} / \mathrm{L})\end{array}$ & $\begin{array}{c}\text { Massa de biocarvão } \\
(\mathrm{mg})\end{array}$ & $\mathrm{pH}$ & $\begin{array}{c}\text { \% de adsorção } \\
\text { biocarvão a } \\
500^{\circ} \mathrm{C}\end{array}$ & $\begin{array}{c}\text { \% de adsorção } \\
\text { biocarvão a } \\
800^{\circ} \mathrm{C}\end{array}$ \\
\hline 40 & 60 & 4 & 40,15 & 8,76 \\
\hline 40 & 60 & 10 & 44,47 & 21,77 \\
\hline 40 & 160 & 4 & 20,99 & 4,74 \\
\hline 40 & 160 & 10 & 66,24 & 17,34 \\
\hline 60 & 60 & 4 & 31,91 & 8,31 \\
\hline 60 & 60 & 10 & 23,97 & 16,34 \\
\hline 60 & 160 & 4 & 30,43 & 4,83 \\
\hline 60 & 160 & 10 & 8,73 & 20,36 \\
\hline 33,2 & 110 & 7 & 54,27 & 34,26 \\
\hline 66,8 & 110 & 7 & 42,73 & 23,99 \\
\hline 50 & 26 & 7 & 36,08 & 4,59 \\
\hline 50 & 194 & 2 & 21,99 & 0,10 \\
\hline 50 & 110 & 12 & 58,95 & 3,20 \\
\hline 50 & 110 & 7 & 49,06 & 3,16 \\
\hline 50 & 110 & 7 & 56,02 & 5,06 \\
\hline 50 & 110 & 7 & 53 & 2,22 \\
\hline 50 & 110 & & & \\
\hline & & 7 & & \\
\hline
\end{tabular}

\subsection{Borra pirolizada a $500^{\circ} \mathrm{C}$.}

Os resultados mostrados na Tabela 1 indicam que o biocarvão pirolisado a $500^{\circ} \mathrm{C}$ adsorveu de forma mais eficiente o thiamethoxam que o biocarvão pirolisado a $800^{\circ} \mathrm{C}$. Tal fato é justificado pela estrutura polar do thiamethoxam. Quando o biocarvão é pirolisado, as altas taxas de temperatura promovem a liberação de grupos voláteis presentes, com consequente perda de grupos que são carregados positiva ou negativamente. A partir desta volatilização perde-se grande parte da sua estrutura polar, permanecendo praticamente, apenas a rede carbônica. Portanto, provavelmente a pirólise a $500^{\circ} \mathrm{C}$ favorece a produção de um adsorvente poroso, com boa área superficial, mas que ainda apresenta grupos funcionais carregados, favorecendo a adsorção do thiamethoxam.

De acordo com as análises estatísticas dos resultados obtidos para a pirólise a $500^{\circ} \mathrm{C}$, as variáveis significativas ao nível de confiança de $95 \%$, foram a concentração do thiamethoxam e a interação concentração/pH, como representado na Figura 1a. O efeito negativo da concentração demonstra que menores concentrações favorecem uma melhor adsorção. Esse resultado indica que adsorção ocorre em monocamadas, ou seja, para cada sítio ativo, apenas uma molécula de thiamethoxam é adsorvida. Observando o gráfico de Pareto, a interação concentração/pH também mostra efeito negativo. Esta interação pode ser melhor entendida 


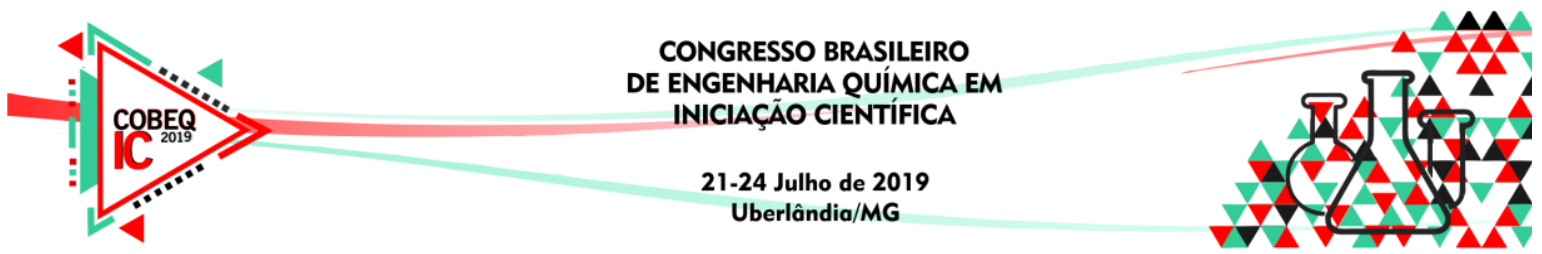

quando se observa a curva de superfície representada na Figura 1b. Quanto menor a concentração do thiamethoxam (efeito negativo) e quanto maior o valor do $\mathrm{pH}$ (efeito positivo), maior à adsorção, ou seja, o processo é mais favorecido. O efeito do $\mathrm{pH}$ é justificado, uma vez que este poderia estar favorecendo a presença de cargas negativas no adsorvente, o que facilitaria a adsorção do thiamethoxam, que apresenta grupos carregados e elétrons livres.

Figura 1: ANOVA para os parâmetros variados no processo de extração com biocarvão

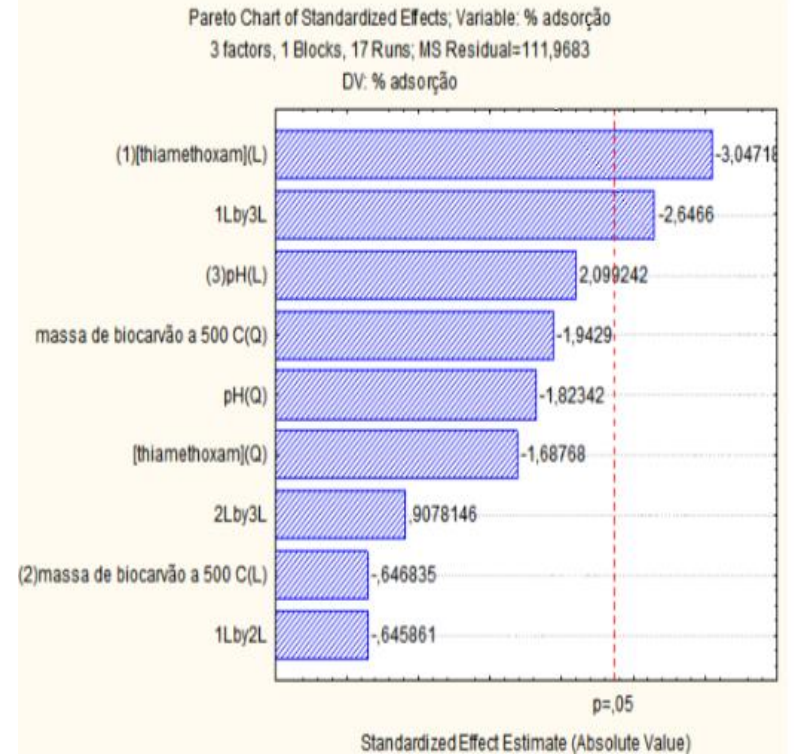

a

Gráfico de Pareto - Estimativas dos efeitos Principais e suas interações na adsorção do thiamethoxam.

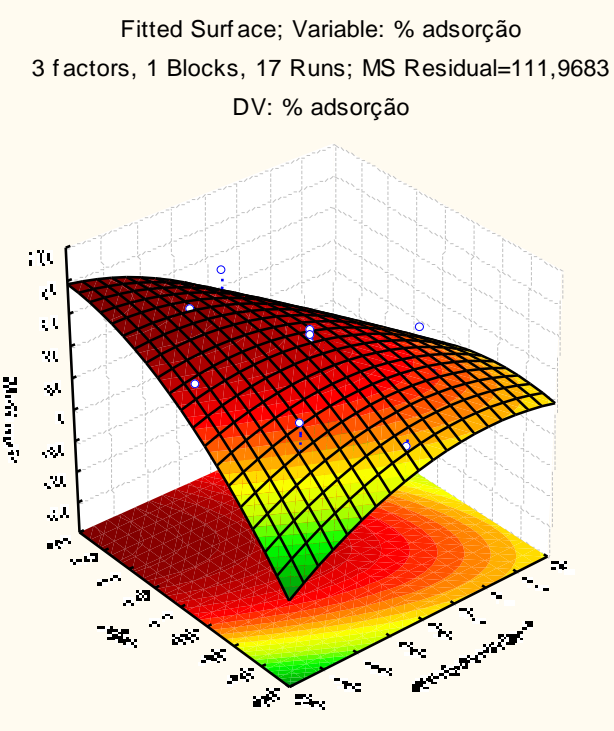

b

Curva de superfície: interação entre pH e concentração de thiamethoxam

Para analisar a relevância estatística do experimento para o biocarvão a $500^{\circ} \mathrm{C}$ realizou-se à Análise de Variância (ANOVA). Os dados são apresentados na Tabela 2. Para confirmação da significância dos parâmetros estudados, realizou-se o teste F. Para que o modelo apresente relevância estatística o valor de $\mathrm{F}$ tabelado deve ser menor que o valor de $\mathrm{F}$ calculado. $\mathrm{O}$ valor de $\mathrm{F}$ calculado foi de 28,63 e o de $\mathrm{F}$ tabelado, por sua vez, 3,74; o valor de F calculado foi, então, muito maior que o de $\mathrm{F}$ tabelado.

Portanto, os dados experimentais são bem representados pelo modelo estudado, demonstrando-se, assim, que o modelo obtido para as variáveis significativas pode ser utilizado para fins preditivos dentro do domínio dos fatores estudados. 


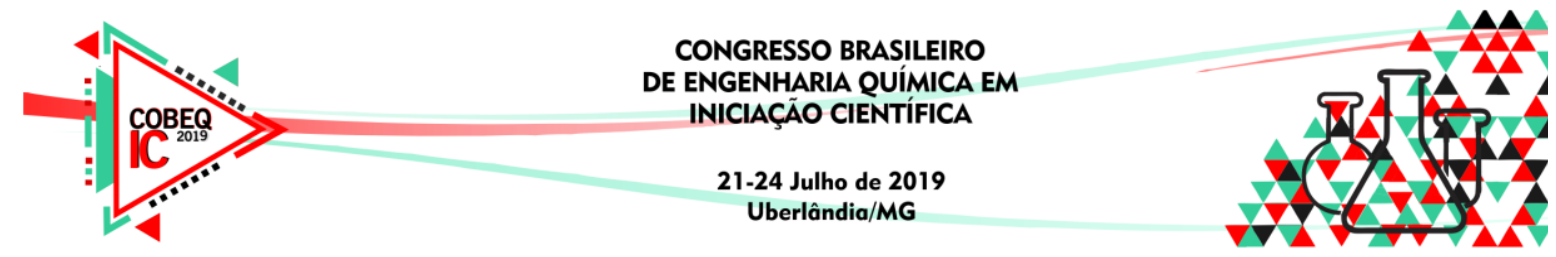

\subsection{Borra pirolisada a $800^{\circ} \mathrm{C}$}

Nesta temperatura, já foram volatilizados todos os grupos funcionais presentes no biocarvão, deixando sua superfície bastante apolar. Tal fato prejudica a adsorção do thiamethoxam, uma vez que o inseticida tem muitos grupos polares não havendo sítios apolares (Figura 3), já que apresenta sítios positivos e negativos em sua molécula. Justifica-se portanto, as baixas taxas de adsorção encontradas (Tabela 1)

Figura 2 - Estrutura do Thiamethoxam<smiles>CN1COCN(Cc2cnc(Cl)s2)/C1=N/[N+](=O)[O-]</smiles>

A Tabela 2 mostra que as variáveis significativas para este processo de adsorção foram a concentração de thiamethoxam e o $\mathrm{pH}$, ambos com efeito positivo, ou seja, quanto maior o pH e a concentração, melhores são as respostas de adsorção. A presença de cargas negativas no meio favorece a adsorção, pois como mencionado anteriormente, o inseticida apresenta grupos carregados e elétrons livres em sua estrutura.

Figura 3: Gráfico de Pareto - Estimativas dos efeitos Principais e suas interações na adsorção do thiamethoxam.

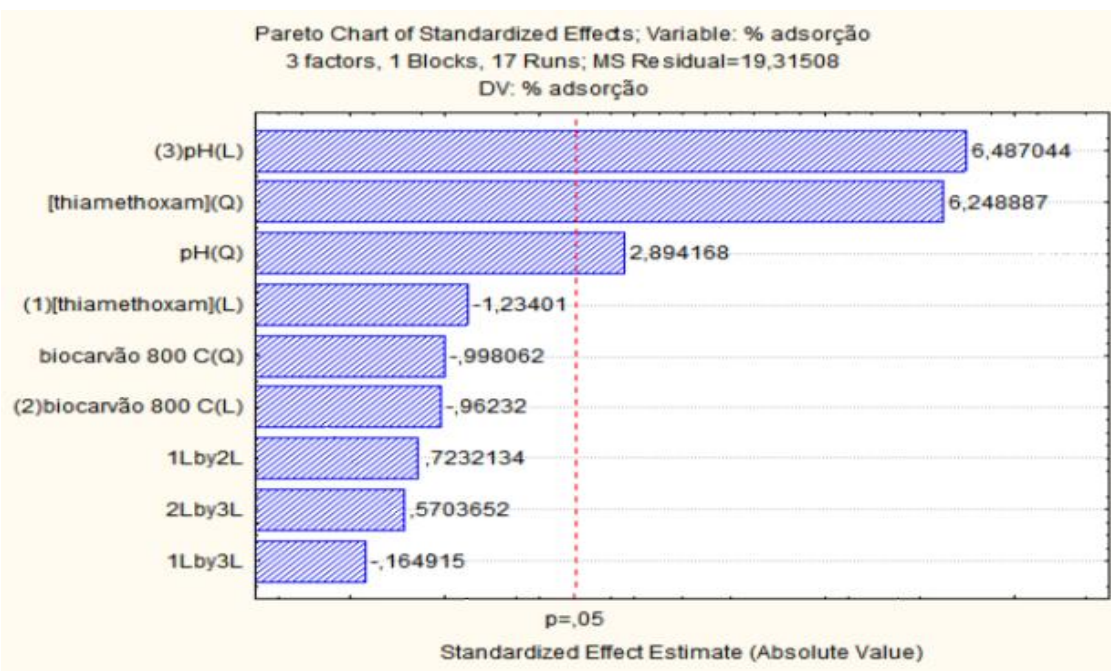

A tabela 2 apresenta os dados obtidos pela ANOVA para o processo de adsorção com biocarvão a $800^{\circ} \mathrm{C}$. O valor de $\mathrm{F}$ calculado foi de 59,83 enquanto o de $\mathrm{F}$ tabelado foi de 3,41 , evidenciando que os experimentos são estatisticamente significativos.

Tabela 2: Análise de variância dos resultados obtidos 


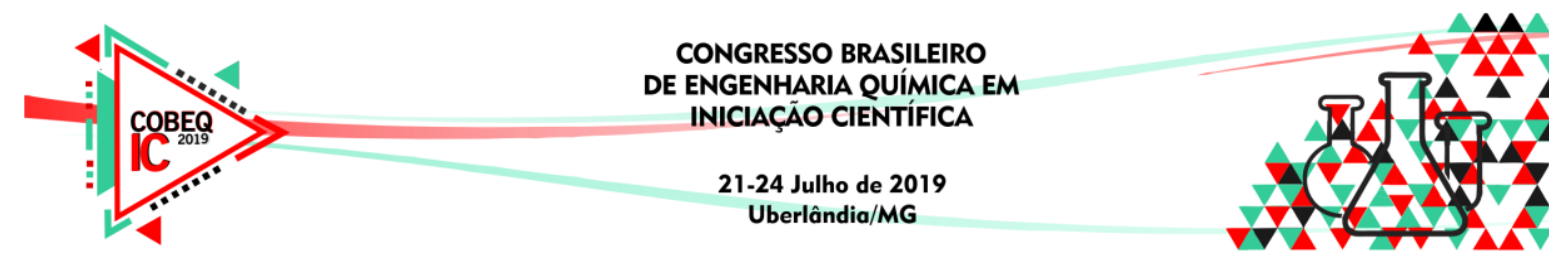

Tabela 2: ANOVA Estimativas dos efeitos principais e suas interações na adsorção do thiamethoxam

\begin{tabular}{|c|c|c|c|c|}
\hline BIOCARVÃO A $500^{\circ} \mathrm{C}$ & $\mathrm{SQ}$ & $\mathrm{GL}$ & SQM & F.CALCULADO \\
\hline Regressão & 3206,259 & 2 & 1603,1295 & 28,63 \\
\hline Resíduo & 783,778 & 14 & 55,984 & \\
\hline Total & 3990,37 & 16 & & \\
\hline BIOCARVÃO A $800^{\circ} \mathrm{C}$ & $\mathrm{SQ}$ & $\mathrm{GL}$ & SQM & F.CALCULADO \\
\hline Regressão & 1866,685 & 3 & 622,228 & 59,83 \\
\hline Resíduo & 135,206 & 13 & 10,4 & \\
\hline Total & 2001,891 & 16 & & \\
\hline
\end{tabular}

\section{CONCLUSÃO}

O biocarvão obtido através da borra pirolisada a $500^{\circ} \mathrm{C}$ foi muito mais eficiente que o obtido a $800{ }^{\circ} \mathrm{C}$. Apesar das elevadas temperaturas proporcionarem adsorventes mais porosos, com elevadas áreas superficiais, temperaturas elevadas como $800{ }^{\circ} \mathrm{C}$ também promovem a volatilização de grupos funcionais polares, deixando a superfície do biocarvão com caráter muito apolar, prejudicando a adsorção do thiamethoxam, que é um inseticida facilmente lixiviado para os corpos d'agua, com elevada polaridade.

\section{REFERÊNCIAS}

ASSOCIAÇÃO BRASILEIRA DA INDÚSTRIA DE CAFÉ. Estatística da produção agrícola: safra 2007/2008. Disponível em: www.abic.com.br/estat_pagricola.html\#cafebene078\&gt Acessado 31 Janeiro. 2019.

AUGUSTO, Danilo. Os danos dos agrotóxicos ao meio ambiente. Radioagência NP, mar. 2011.

BACHA, Carlos José Caetano. Economia e política agrícola no Brasil. Editora Atlas, São Paulo, 2004.

MELLO, Fernando Homem de. Construindo uma nova política agrícola. Congresso da Sober, Fortaleza, 2006.

TAVARES, S .et al. Avaliação dos efeitos fisiológicos de thiamethoxam no tratamento de sementes de soja. Revista de Agricultura, v.82, n.1, p.48-67, 2007.

\section{AGRADECIMENTOS}

À CNPQ/FAPEMIG ( SICONV -793988/2013). 